\title{
Enterprise Resource Planning Tools Management in Private Higher Education in South Africa
}

\author{
Joseph Mithi, Saths Govender \\ Durban University of Technology, South Africa \\ 21751970@dut4life.ac.za,jmithidr1@gmail.com,dr1govender@telkomsa.net, sathsgovender4@gmail.com
}

\begin{abstract}
In this research on Enterprise Resource Planning Tools Management in Private Higher Education in South Africa, the study objective was to determine critical issues influencing Enterprise Resource Planning (ERP) tools selection in academic management in Private Higher Education Institutions (PHEIs) in South Africa. A mixed-methods (qualitative and quantitative) research methodology was used to triangulate the results of the research from an interpretive position. The research analyzed and reported on subjective and quantitative data to ascertain knowledge about the participants' recognition of critical issues affecting the management of ERP tools in academic management in PHEIs in South Africa. In this study, the following groups of participants were purposefully sampled: students, lecturers and management staff working in the three PHEIs in Gauteng. The study found that academic attainment in PHEIs could be enhanced through ERP tools management in ICT integration. The research outcomes suggest that there is enhanced coaching and students' personal interactions through online conference tools, a practice that may be backed up and carry the same weight and recognition as physical learning contact hours. Issues of integration in the selection of any robust, dynamic PHEI tools may call for a firm's financial readiness and company-wide consultations with potential users of the system. Any HE ERP system that does not have a student portal, without integrated online issues of applications, checking of results, enhancement of teaching and learning but partly integrating one or two departments in isolation to others, may not be considered fit or robust as a higher educational ERP tool.
\end{abstract}

Keywords: Academic attainment, Private Higher Education Institutions (PHEIs), Enterprise Resource Planning (ERP) tools, Information and Communication Technology (ICT); Higher Education (HE).

\section{Introduction}

Enterprise Resource Planning (ERP) is described as the ability to convey an incorporated suite of business applications. ERP tools share a typical procedure and information model covering wide and significant operational start to finish forms. Examples are found in the areas of accounting, human resources management, production, administration, distribution and supply chain networks.

Enterprise Resource Planning Systems (ERPs): ERP applications mechanize, robotize or automate and support an extent of administrative and operational business forms over different endeavors, including a line of business, Customer Relationship Management (CRM), managerial and asset administrative functions of a business. ERP establishments are expensive and complex endeavors and some firms battle to characterize or depict the business benefits thereof. ERP benefits, as categorized by (Gartner, 2019), follow as an impetus for business advancement; a stage for business process proficiency; a process institutionalization vehicle; and Information Communications Technology (ICT) as a cost-saving channel.

The Research Problem: According to (Debrosse-Bruno, 2017), ERPs present an organizational administration issue for various enterprises, including Private Higher Education Institutions (PHEIs), because they are expensive to establish and normally neglect to meet foreseen desires because of the sort of tasks that ERPs support. The importance of discoveries is hoped to understand the research inquiries of the goals of this study. The audit of writing as an auxiliary information source was likewise viewed as important to expand the comprehension of Enterprise Resource Planning tools management in Private Higher Education in South Africa: critical issues influencing Enterprise Resource Planning tools in scholarly administration within the inquiry of a contextual examination, to explore and determine the inner and outer factors that influence overseeing of ERP instruments for coordinated administration frameworks. The study aimed at developing and recommending a system within best practices towards continuous improvement.

Importance of Tools Management: The use of Enterprise Resource Planning tools Management in Private Higher Education is currently dominating discourses on how to attain greater efficiencies and improved 
outcomes in education in South Africa. It is for this reason that this study seeks to determine the issues influencing ERP tools management in PHEIs.

The History of ERP and Evolution: ERP providers and fashioners must consider client needs and concerns in the planning of ERP bundles. Understanding client qualities and their communication will prompt better advantages. For instance, when ERP clients have little computer access, framework fashioners ought to put more into making the frameworks less demanding to use to encourage more framework effects and advantages. "On the development of the Enterprise Resource Planning Systems (ERPs)", (Abdullah \& Babaseheb, 2017) postulate that ERP has come a long way and has undergone various stages of transformation. The first stage was in the mid-twentieth century in that the different offices inside associations used to work autonomously. These offices were frequently named practical storehouses. Normally, frameworks were denied the advantages of coordination. The "advancement of ERP frameworks nearly took after the significant improvements in the field of Pocket Computer (PC) equipment and programming frameworks." Likewise, on account of the immense multifaceted nature of business capacities and changing of aggressive conditions, associations began hunting down new innovations to satisfy their capacities or necessities. Along these lines, from 1960 upwards, "most associations planned, created and actualized concentrated figuring frameworks, generally computerizing their stock control frameworks, utilizing stock control bundles".

This was the original processing framework brought together. Additionally, the second era was Material Prerequisites Arranging or Material Requirements Planning (MRP) frameworks, which were created in the era of 1970 and included principally arranging the items or parts necessary as indicated by the main generation plan. The third era of the new programming frameworks called Assembling Assets Arranging (MRP II) was presented in the 1980s with an accentuation on streamlining fabricating forms by integrating the materials with generation prerequisites. MRP II included territories, for example, shop floor and dissemination administration; venture administration; human assets and designing". Furthermore, the fourth era was Endeavour Asset Arranging (ERP) frameworks, which initially showed up at the end of 1980 to the beginning of 1990, with the intensity of coordinating business-wide operations. Given the technological advancements of MRP and MRP II, ERP frameworks coordinate business forms, including all capacities as assembling, circulation, bookkeeping, budgets, human asset administration, venture administration, stock administration and support, transportation, giving availability, perceivability and consistency over the Enterprise. As reported from 1990 to date, ERP merchants or Providers have included more modules and capacities bringing forth the expanded ERPs.

ERP Awareness: Regarding expanded ERPs, as revealed by (Abugabah, Sanzogni, \& Alfarraj, 2015), in Enterprise Resource Planning (ERP) Frameworks, framework quality, undertaking innovation "fit and data quality are the essential factors that prompt better end-client" observation. This confirms the propriety of expanding data framework models as a valuable method to give all the more ground-breaking bits of knowledge to client perspectives and framework effect. Even though the researched factors clarified a huge segment of the fluctuation in client recognition, there is a part of the difference that remains unexplained. There has been a general absence of mindfulness reported about the significance of assessing ERP frameworks from a client's point of view. The primary focal point of past investigations was either on basic components and usage issues or client acknowledgment and fulfillment. In the researcher's view, with the dynamic changes in organizations to adapt to expanding requests in consumer loyalty and undertaking development, PHIs are embracing virtual institutions. Hence this study underscored the significance of this issue in exploring critical issues influencing_ERP tools management in higher education administration. As highlighted from a review of general literature accompanying this study, authors have announced that it was of principal significance.

To build up a proof-based approach to the utilization of ERP models inside ERP administration's regularly evolving region. General assessments on post-ERP execution were urged to happen frequently for recognizable proof of non-conformists and towards constant change. Crafted by the previously mentioned authors, it is recommended to the Specialist to be watchful for extra factors that could affect ERP device or tools administration. Moreover, with respect to the plan of a coordinated structure and advancement of proper procedures as a progressive tool other than existing quality models in administration frameworks, 
observational investigations that came about gave a head start to future research for a more successful combination in ERP administration. In light of the above perspective, there was a hypothesis that there ought to be a careful readiness of an aggregate quality administration data framework or Total Quality Management Information System (TQMIS) on current practices in ERP administration or principal innovation, emphasizing fundamental hardware for access to the web and the system framework. Relating to TQMIS, a contention was introduced that the apparent successful ERP administration utilized an integrative approach intending.

To accomplish an adjustment or balance amongst certain key institutional components the writings above demonstrate that for the last couple of decades, advanced education establishments have been open to the solicitations of changed overall business conditions to upgrade their suitability. The motivation for this study was to assess the execution of an undertaking's asset arranging (ERP) structure in training and the related points of interest, with an accentuation on undergraduate students' execution, while applying a framework application item course of action.

\section{Literature Review}

This review of literature on dissected accessible ERP frameworks was conducted to address this study's research questions and critical concerns. The motivation behind this exploration or the purpose of this writing audit was to determine and build knowledge around critical issues influencing ERP tools management in PHEIs in South Africa.

\section{Review of Literature on Previous Empirical Studies}

Use of Models in the Integrated ERP Management System and their Applicability: Findings from previous studies by (Peng \& Miguel, 2017), (Schniederjans \& Yadav, 2013), (Alhirz \& Sajeev, 2015), reported that it was of paramount importance to establish an evidence-based approach in the use of ERP models within ERP management's ever-changing area. Regular evaluations on post-ERP implementation were greatly encouraged to be taking place regularly for the identification of misfits and towards continuous improvement. The work of the aforementioned authors suggested to the Researcher to be on the lookout for additional factors that could have an influence on ERP tools management. The study sought to explore the challenges influencing the managing of the ERP tools currently in use in the selected PHEIs. In agreement with DeLone \& McLean's Model (the Information Systems (IS) in general), the Foundations Systems Approach was used by (Somerville \& Mirjamdotter, 2014), to study the collaborative information approaches reflecting knowledge creation and experiences through transferrable learning capabilities in an organization. The systems approach indicated that sustainable continuous learning in an institution emanates from collaborative practices and system functionalities.

As applied to this study, this theory held that the domain knowledge transfer was to be at the center of user experiences in the ERP system, with the view of not just looking at the technological fit and information quality, but also post-ERP implementation phase user experiences. This Foundation Systems Approach provided an opportunity for exploring insights into user aspects and ERP tools management for integrated activities. Consequently, the Systems thinking in assessing individual capacities reflected within DeLone \& McLean's theory as applied by (Jaradat, 2014), extrapolating the spawn and lagging brought about as a result of exponential technological advances, brought an understanding of the methods that bridged such a gap or divide. (Abugabah, Sanzogni, \& Alfarraj, 2015), in tandem with (Jaradat, 2014), showed that most studies in ERP systems focused on factors that affect ERP implementation in terms of user acceptance and satisfaction, with less emphasis on antecedents like user groups and their computer knowledge experiences within the system. As such, this area presents a gap in the study in investigating the users' perspective and awareness of ERP tools management. Furthermore, the ERP systems in relation to DeLone \& McLean's model have confirmed that there are few conceptual.

Theoretical frameworks in place to guide the implemented ERPs, hence the application of IS general theories ( (Kalema, Olugbara, \& Kekwaletswe, 2014). Success Factor Theory, as developed by (Kalema, Olugbara, \& Kekwaletswe, 2014), brought a cross-impact analysis on "a wide range of factors that influence the success of ERP systems" in African Universities. This theory indicated that factors impeding success were closely 
examined within the Integrated Tertiary Software (ITS) system in deriving what constituted successful implementation and the use of ERP systems. The cross-impact analysis factors were presented as being complex and costly. At the center of IT'S are the daily use and perceptions of stakeholders of the ERP system. As applied to the research, this presented a gap in exploring the critical factors influencing ERP tools management. The research also proposed to draw on the premise that there was a recommendation for the consideration of indirect relationships, demanding a further investigation in specific areas within the crossimpact analysis of the ERP system (Kalema, Olugbara, \& Kekwaletswe, 2014). Generally, Venture Resource Planning (Enterprise Resource Planning usage had difficulties with a specific end goal to expand the execution (Wijawa, Kosala, Meyliana, \& Prabowo, 2017, p. 513). The motivation behind the examination was to propose an elective approach for the ERP framework, with a specific end goal to improve the association execution.

The technique for the approach was a Systematic Literature Review (SLR) for building up a spry (agile) structure for an ERP framework that included 54 papers for inquiry. The examination discoveries uncovered a coordinated structure as an instrument for a more improved ERP framework. The exploration propelled data from different analysts and practices to build up a deft structure for ERP framework as an elective arrangement "keeping in mind the end goal to upgrade the execution and expanding upper hand of associations" towards business competitive advantage. ERP Agility was clarified as the ERP device territories of cost, quality, reliability and adaptability that went past the capacity to react quickly to any unforeseen changes in the business condition (Wijawa, Kosala, Meyliana, \& Prabowo, 2017, p. 513). Furthermore, (Babaian, Xu, \& Wendy, 2017), demonstrated that few ongoing investigations of ERP framework interfaces have affirmed that their poor ease of use blocks laborer profitability, despite the enormous speculations that organizations make in supporting and preparing clients or users. Ease-of-use challenges emerged from the unpredictability of ERP frameworks, which were planned as a general instrument for plenty of authoritative practices and settings. Figuring out how to work inside an unreasonably tremendous landscape of ERP assignment pages and parameters was a noteworthy test for most ERP clients.

The proposed arrangement in this study conducted was dependent on the framework itself to share errand and process data, keeping in mind the end goal to direct clients through learning and playing out their business assignments with the framework. This point of view emerged from utilizing the human-PC joint effort way to deal with the plan of User Interfaces, which were applied as a directing system for the research. This research displayed two interface segments for giving ERP framework clients assignment and process direction: Computerized Playback and Intelligent Process Representation. The oddity of approach originated from utilizing the historical backdrop of past cooperation's to progressively make enlivened exhibitions out of assignment interfaces and to give an intuitive graphical guide to the present procedure being dealt with by the client. The above research presented an opportunity for PHEIs to explore how ERP practices, amongst other factors, influenced ERP agility within the ERP tools integration. Regarding ERP tools, Quality Management had picked up in ubiquity chiefly because of expanding client cognizance of value and developing universal focused weight with the expanding need to consider the developing requests of the clients and to adapt to increasing rivalry. The quality introduction was the fitting method to stay focused.

The absolute, most basic factor required for the survival and development of an association is quality. This had turned out to be significantly more imperative in extending worldwide commercial centers, confronting real difficulties through rivalry amongst players within and through expanded clients' desires. Organizations giving quality items and administration had increased their aggressive edge and more noteworthy pieces of the overall ERPs. Step by step, the number of instructive establishments was expanding and the vast majority of them were being overseen by private administration. As benefit was their genuine concern, part of the value was being disregarded. Today, higher instructive Institutions are confronted with worldwide rivalry and a ton of issues. For example, low graduation rates, higher drop-out rates, less employability and so forth. Instructive associations must adjust quality approaches to enhance the nature of advanced education. This study looked at the integrative models or frameworks and their applicability in PHE1s. The expansion of advances was changing economies from various perspectives. This was especially valid in the purchaser confronting enterprises where the development of computerized administrations was empowering novel offers, nearer buyer connections. 
More prominent mechanization of customer confronting business forms (AIS e Library, 2017). Applied to PHEIs, there was an opportunity to explore the ERP tools integration within the applicable frameworks. New computerized benefits in customer confronting associations offered novel offers, nearer buyer connections, and higher mechanization of shopper confronting forms. Changing to completely advanced administrations required an association to get particular capacities. This article exhibited an association's ability to test its present capacities and distinguish gaps. Two top-to-bottom contextual investigations exhibited the utilization of the model and recognized the capacities in pressing need of change. The suggestions were worked around four situations for utilizing the model. The reference to the model demonstrated the possibility for evaluating the condition of shopper confronting advanced administrations. Customer Relationship Management (CRM) is referred to as Comprehensive Academic Management (CMMI) for administration and Advanced Customer Relationship Management System (CMMI-SVC). It was an individual from the ability development show combination (CMMI) group of process level change and examination programs and portrayed great practices in 24 process regions. For example, in prerequisites administration, limit.

Accessibility administration and hierarchical process definition. CMMI-SVC gives general direction on the advancement of customer relationship management systems and associated benefits, yet needs particular bearing for the outline of computerized administrations. For instance, it addresses overseeing limits without talking about the particular innovation-related abilities of advanced administrations, for example, client information administration (Wulf, Mettler, \& Brenner, 2017). From the above, the abnormal state of variety in the degree of advanced abilities proposed organizations confront impressive difficulties in building up the essential transformational capacities. These difficulties incorporate constrained access to ability; an absence of business understanding and hierarchical dexterity; the non-appearance of a trial mentality; and wrong Information Technology (IT) frameworks. Managers looking for help on the best way to advance capacities and needing to gain from the gathered encounters of others routinely swung to reference models that depicted basic abilities and gave examples of how those capacities advanced after some time. Such models were extremely famous because they empowered organizations to survey their present state and recognize the future states for which they yearned for. The models were regularly scrutinized for overlooking an association's situational setting and for producing a bureaucratic mentality, which tended to block as opposed to empowering development.

Relating to PHEIs, the above examination featured the need to take a gander at the utilization of models in the coordination of ERP administration frameworks towards scholastic achievement. As shown by (Khan, et al., 2017), firms have a place with social groups that are specialists in making recent information from conditions. Learning that is produced from past involvement and conditions may influence an association's procedure decidedly. To prepare learning osmosis better, it requires solid initiative capacities that can perceive information from conditions in the feeling of chance and danger. In this story, the impact of absorptive limit (AL) and predominant rationale (PDR) are examined regarding big business asset arranging (ERP). Dynamic Capacities (DC) of the best directors to keep the learning from grassroots and absorb it as shown by the requirements that enhance a company's venture asset arranging (ERP). The fundamental concentration in the examination was information and how top-level supervisors utilize routine learning to get future advantages for their firms. The model was figured from past writing that demonstrates the impact of absorptive limit, its subsets and predominant rationale and its measurements on ERP osmosis. For this investigation, the examination was about Chinese firms in Hefei City, Anhui territory in China.

Hefei is one of the quickest creating and developing financial centers in China. Workers from the top-level were the aim of gathering data in this research. The outcomes showed that the absorptive limit and overwhelming rationale affected ERP in Chinese firms. These did not just build the profitability and execution of the firm, but additionally helped in the designation of assets and basic leadership procedures to remain in the dynamic market and contradict any sort of dangers. The outcomes showed a positive connection between every one factor. This investigation from the Chinese firms from the area of Anhui might be applied to PHEIs in South Africa in discovering systems that may improve the advantages in the ERP apparatuses administration inside the coordinated condition. Consequently, (Awa, Ojiabo, \& Orokor, 2017) presented an advancement affiliation condition referred to as the Technological Organizational Environment (T-O-E) framework in which the association amongst the appointment and the factors inside the settings of development, affiliation, condition and task were authentically maintained. However, some had negative 
coefficients. T-O-E logical characterization is seen to acknowledge effective scholarly honor, yet it occasionally maintained unmistakable errors and individual factors. Regardless of how errand and individual settings had been freely tended.

To by Technological Task Development Fit (TTF) and bound by the theory of Affirmation and Usage of Advancement (Unified Theory of Acceptance and Use of Technology, UTAUT) independently, the explanation behind this paper was to supplement and besides grow the T-O-E's bits of learning by planning TTF and UTAUT frameworks and making and precisely testing a 12 -factor structure that crosses five settings. The system of the approach used was reviewing data that was generally accumulated from six get-togethers of little organizational attempts with strong errands in Port Harcourt, Nigeria. The technique for assessing was purposive and used the snowball method, while the examination included found out the likelihood of slideback. It was uncovered that the association amongst gatherings and the segments inside the settings of advancement, affiliations, conditions and undertakings were genuinely maintained. However, some had negative coefficients. For a particular setting, social factors had a genuinely essential negative coefficient. Yet a ravenous drive was not quantifiably maintained. The study conducted is confined by its extension. Along these lines, extended it requires data to apply the disclosures to various regions/wanders.

Factor in the utilization and post-apportionment stages and business-to-business gatherings to produce a more merged and widely inclusive determination framework. The disclosures bolster dealers and system makers to place more premiums on progressive and undertaking factors than on mechanical, regular and individual factors, and to make instructed and promoted programs that would intrigue certified and potential adopters and make them progress in the unwavering quality venturing initiatives (Awa, Ojiabo, \& Orokor, 2017). This paper included creating a research development gathering as it used factors inside the T-O-E, TTF and UTAUT frameworks to clear up the apportionment of progressions and to set up the shrouded associations amongst T-O-E factors in planning other profitable structures. The confinements and disclosures from this study understand an open entryway, enabling the change and usage of a framework in regulating ERP courses of action or instruments in private higher education. (Ruivo, Oliviera, \& Mestre, 2017), created and tried a hypothetical model to gauge the effect of big business asset arranging (ERP) and client relationship administration (CRA) frameworks and directing connections of framework and process mix on business esteem. ERP and CRA frameworks were broken down "with the asset-based view hypothesis and estimated by their effect on business esteem, bearing in mind the control of framework and process joining.

The model was tried and broken down with information gathered by Microsoft from firms that have, embraced both ERP and CRA frameworks in their association. The ERP framework was observed to be a vital resource for business esteem. However, CRA frameworks' effect on business esteem was observed to not be noteworthy. Framework incorporation as an arbitrator of the ERP or CRA framework was observed to be not critical, but rather had a positive and noteworthy effect on business esteem. For process reconciliation, the examination found that it was critical while directing the CRA framework variable. The model showed that the directing effects of the framework and process incorporation were essential factors for understanding the joint business estimation of ERP and CRA. Embracing an ERP framework and guaranteeing framework reconciliation had an immediate effect on business esteem. For a CRA framework to positively affect business esteem, process combination with ERP framework must be guaranteed. This research gave additional information on how ERP and CRA frameworks, utilized together, may decidedly affect an incentive from IT ventures, and how framework reconciliation and process mix gave business esteem. The above empirical study by (Ruivo, Oliviera, \& Mestre, 2017, p. 8) provides the impetus to explore the incorporated ERP instruments in private higher schooling towards academic excellence. The next section looks at current practices in ERP tools management.

Current Practices in Place to ERP Management: Findings by (Srima \& Wannapiroon, 2013), (Tabbara, 2016) \& (Al-Mashari, 2017) postulate that there should be a thorough preparation of Total Quality Management Information System (TQMIS) in current practices in ERP management in terms of principle or fundamental technology, placing a focus on basic equipment for access to the Internet and the network system. The above authors argue that the perceived effective ERP management uses an integrative approach, aiming to achieve a balance amongst certain key institutional elements. The findings in this section were pertinent to this research in that there was the regard of network systems and Internet connections at the 
heart of the dominant technology. This resonated well in giving an interesting reason to exploit the gaps in ERP tools management misfits. It is shown that academic associations spend a great deal of cash, time, and assets on big business framework (ERP) execution. However, they regularly do not understand the normal advantages of these mind-boggling frameworks. There was a gap in the literature in giving adequate knowledge on the usage procedure in terms of how ERP devices may affect or add to a culture change.

The reason for the exploration, led by (Skoumpopoulou \& Waring, 2017, p. 1), was to address the gap in the ERP writings around culture by investigating the usage that was attempted in an expansive UK college. This examination added to the advanced education ERP writing through an inside-out investigation of an ERP Key Data Innovation Administration (KDIA) execution by a college "in the UK. The investigation was attempted over a three-year time-frame, where one creator was located within the association. Utilizing a social examination system, the broad rich information was broken down, and the results showed KDIA has affected the way of life of the college. The innovation's inflexible structure has forced many progressions that had not been foreseen. ERPs have as of late developed in the higher education institutions where they are planned to help the administration of undergraduate information and give vital administration data. Although there are many studies that have researched imperative parts of the execution of ERPs, one region that seems to have been 'under-looked into' is how these frameworks are embroiled in culture change inside associations. The after-effects of this investigation would empower administrators and additionally IT masters to increase rich bits of knowledge.

In to tools or solutions management in the PHEIs to utilize this learning for future usage. Regarding the above, it may arguably be seen that PHEIs had to re-look at their internal cultures. As explained by (Kasemsap, 2018) in the study directed, there was a disclosure review of learning exchange; information exchange, work portability, and work assorted variety; learning exchange and backup points of view; hindrances to information exchange; information exchange and absorptive limit; learning exchange and information securing; learning exchange and virtual groups; and the propelled issues of learning a move in current associations. Exchanging information was a continuous movement of picking up, changing and making strides. At the authoritative level, information exchange shows itself through changes in the learning of a unit. Best learning exchange endeavors effectively include both the wellspring of the information and its recipients. Setting up execution desires for the individuals who will utilize the learning further tests the estimation of the exchange. Institutions considering or utilizing information exchange forms ought to persistently assess their web-based life status. The advantages of information exchange for working environments incorporate increments in efficiency, speed, readiness, benefits and development.

In PHEIs, this research exhibited a superior chance to explore routes in how ERPs might be utilized as a social center-point in the production of information that might be regarded as profitable towards the grant of research, like campus distributions center-points inside and across the board ERP frameworks, guided by the ERP tools administration frameworks, other than simply utilizing ERPs for ordinary regular learning connections or correspondence. To support the ERP business execution in HE above and amidst different procedures cross-wise over three areas, a university administration framework that was not up and coming and a loss of learning on account of statistic changes and undocumented conflicting procedures, Jade College of Connected Science executed a grounds administration framework created by Hochschul Information's Framework. This framework incorporated a coordinated reference show for forms that were identified by the administration team. The college needed to utilize basic norms and required a guide given best practices. Actualizing business process administration gave a chance to report, institutionalize and unify forms within their respective areas (Buhrig, Schoormann, \& Knackstedt, 2018, pp. 577-592). Usage of the Campus Administrative framework and reference forms was organized in steps that could be portrayed.

Utilizing a Business Procedure Administration life cycle display that spreads initialization of ERP; process distinguishing proof; a process of revelation; process investigation; process upgrade; process execution and process checking. Every one of these means was specifically identified with the utilization of Hochschul Information's Framework reference model across the board to gain proposals given best practices. Both expected and surprising outcomes were acquired from the execution of the Campus administration framework, exemplifying the institutionalization of procedures crosswise over three areas was enhanced by embracing best practices, and inward workshops to institutionalize procedures. This fortified Jade College's 
general camaraderie or unity of direction. Singular boundaries to utilizing process models and process documentation were decreased and a Business Procedure Administration steady culture was created to such an extent that a few offices started to report different procedures and to consider the usage of a more extensive Business Process Administration division. Five essential exercises were found amidst the venture. For example, situating existing arrangements like process reference models that bolstered the initialization of new undertakings and institutionalization restricted the included partners' imagination. Rules for reliably archiving the usage's advance were essential to effortlessly give important data to all partners constantly.

Incorporating significant partners into the procedure empowered the norms over various areas to be resolved, and restricted venture assets were considered with a specific end goal to design appropriate and attainable activities (Buhrig, Schoormann, \& Knackstedt, 2018). The above proposals continuing from the examination above presented a gap to investigate current practices into private advanced education ERPs. As indicated by (Comuzzi \& Parhizkar, 2017), ERPs are difficult to keep up with since they insert an expansive part of authoritative information and assignments which are frequently interwoven and exceptionally related. The explanation leading the investigation proposed a strategy for ERP present execution change administration to help business experts amidst perfective support. The approach drew parallel with building change administration and considered the means of mapping the conditions amongst ERP apparatuses; understanding the gradually expanding influences of progress and characterizing measurements to evaluate and survey the effect of progress. The strategy was explained on account of ERP frameworks, for which a device had additionally been actualized and assessed by ERP usage specialists. Specialists decidedly assessed the proposed system. General outline standards to substantiate the procedure on account of frameworks other than ERP had been inferred.

While existing ERPs change administration procedures helped to distinguish the requirement for change, the proposed strategy was said to structure the change procedure, supporting the errand of perfective upkeep proficiently. Stemming from the examination above, there was a chance to continue exploring ERP current practices in PHEIs towards better ERP tools arrangement administration. The investigation by (Thennakoon, Bandara, French, \& Mathiesen, 2018, pp. 487-500) illuminated that there was a wide assertion that ERP arrangement, people from all levels of a relationship in-process organization "activities and process" accepting was a vital supporter of the accomplishment or dissatisfaction, and viability of business process organization (BPO). BPO getting ready was given in all BPO exercises and incorporated the wander of critical budgetary, human, information and diverse resources. In any case, little research had focused on this domain. In this way, there was nonattendance of bearing for a relationship in driving worth, including BPO getting ready. The inspiration driving the examination was to merge the current disseminated data on BPO getting ready as an unmistakable composition study to depict the present work.

Recognize gaps and propose a program of work for what was to come. A sorted written work overview was directed to grasp the present status of composing planning in the space of BPO. Upon a fundamental review of ninety appropriations, 64 creations, dispersed between 1994 and 2015, were isolated and investigated considering their criticality to answer the examination question composing of planning people for BPO. This examination proposed an investigation "design in light of this. A Grounded Theory coding approach was used, where NVivo 10 was used as a gadget to help the examination. 234 codes addressing rising subjects were inductively perceived from the data. These codes were moreover broken down, achieving eight focus subjects identifying with getting ready in the Business Process Management (BPM) setting. The study displayed an unmistakable illustrative outline of the back-and-forth movement status of research in BPO, recognizing gaps in the written work and demonstrated a research inspiration that reinforced a call for action. The study above presented a gap that explored the present practices within the ERP tools arrangements administration in PHEIs.

\section{Lessons Learned}

ERP as "Software as a Service (Saas)": In terms of the developments or the expansion of ERP instruments and the administration thereof, the more noteworthy commitment was from the ERP-appropriated condition (clients) instead of simply getting arrangements on the web or somewhere else. It was this reality that the study investigated. ERP was viewed as one of the spaces as a Software as a service (Saas) inside distributed 
computing (Elmonem, Nasr , \& Gheith, 2017). As stipulated by (Yatika \& Hasija, 2017), within the integrated ERP management system, the expanded rivalry had persuaded numerous senior chiefs in assembling associations to assess their focused techniques and assembling hones with the point of enhancing hierarchical execution. Endurance in an engaged space has reliably been a test in the cutting edge of technology. In these days of globalization, advancing or progressing digital firms think that it is difficult to endure competition, except if they have a competitive advantage. The experimental proof proposes that competent administrations of a high caliber will out-perform the opposition advantages and increase the market entrance rate.

\section{Methodology}

The Method Applied: A mixed-method was used to triangulate the results as "all methods individually are flawed, but these limitations could be mitigated through mixed methods research, which combines methodologies to provide better answers to research questions (Turner, Cardinal , \& Burton, 2017, pp. 243267). (Cresswell, 2018) agrees with (Sekaran \& Bougie, 2018, p. 256) by stating that the "Mixed methods techniques are a way to deal with requests, including gathering both quantitative and qualitative information, incorporating the two types of information, and utilizing particular plans that may include philosophical presumptions and hypothetical systems. The central presumption of this type of request is that the mix of subjective and quantitative methodologies gives a more total comprehension of an examination issue than one approach" alone. The study utilized multiple sources of data collection in a mixed manner, such as the use of interviews and a focus group (in-depth interviews) in qualitative investigations. In using a survey as a quantitative method, the questionnaire was administered to 100 participants as the sample size, comprising students, lecturers and management staff out of a population size of 10500 participants.

\section{Results and Discussion}

Findings of the study on ERP tools management in Private Higher Education in South Africa, In comparison with previous studies. It may be considered paramount that a PHEI establishes robust, dynamic, agile and versatile ERP tools that may be easily punctuated or added to existing tools within the ERP integration of tools. In this way, it may become simple for the company to adjust in many areas in managing and controlling security features in the ERP tools. One example may be that of finances, which may not allow students that owe fees to the institution to access their student account with academic information. When private institutions do go that route, of complete HE ERP integration, it might be helpful to sustain an HEI's competitive advantage.

\section{Conclusion and Recommendations}

Regarding ERP tools, Quality Management had picked up in ubiquity chiefly as a result of expanding client cognizance of value and developing universal focused weight with the expanding need to take into account the developing requests of the clients and to adapt to increasing rivalry. The quality introduction was by all accounts the fitting methodology to stay focused. The absolute, most basic factor required for the survival and development of an association is quality. This had turned out to be significantly more imperative in extending worldwide commercial centers confronting real difficulties through rivalry amongst players within and through expanded clients' desires. Organizations giving quality items and administration had increased their aggressive edge and more noteworthy pieces of the overall ERPs. Step by step, the number of instructive establishments was expanding and the vast majority of them were being overseen by private administration. Today, higher instructive institutions are confronted with worldwide rivalry and a ton of issues. For example, low graduation rates, higher drop-out rates, less employability and so forth. Accordingly, instructive associations must adjust quality approaches to enhance the nature of advanced education.

This study looked at the integrative models or frameworks and their applicability in PHE1s. In turn, the expansion of advances was changing economies from various perspectives. This was especially valid in the purchaser confronting enterprises where the development of computerized administrations was empowering novel offers, nearer buyer connections and more prominent mechanization of customer confronting business forms (AIS e Library, 2017). Applied to PHEIs, there was an opportunity to explore the 
ERP tools integration within the applicable frameworks. It may be considered paramount that a PHEI establishes robust, dynamic, agile and versatile ERP tools that may be easily punctuated or added to existing tools within the ERP integration of tools. In this way, it may become simple for the company to adjust in many areas in managing and controlling security features in the ERP tools. One example may be that of finances, which may not allow students that owe fees to the institution to access their student account with academic information. When private institutions do go that route, of complete HE ERP integration, it might be helpful to sustain an HEI's competitive advantage.

Way Forward to Cope the Challenge: The study recommends that there may be a need for HE departments that are stakeholders or those that assist PHEIs to help in the formulation of a standardized HE ERP architectural system that may meet most needs of the PHE ERP tools. ERPs that are found in the market as already configured Learning Management Systems (LMS) may be expensive to buy and manage by many PHEIs. A standardized system may be easy to manage and supervise within a certain policy. The standardized ERP is not to be enforced upon PHEIs, but should be a matter of choice in adopting it or not. Private higher education institutions may integrate or have their own parallel ERP systems to the standardized one. Having education ERP tools with a vibrant website may be considered a competitive bid by many potential customers or students, a place to enroll with. Vibrant PHEI ERP tools with a dynamic HE website may be perceived as the online university of the moment by numerous potential clients.

\section{References}

Abdullah, A. M. \& Babaseheb. (2017). Evolution of Enterprise Resource Planning. Excel Journal of Engineering Technology and Management Science. An International Multidisciplinary Journal, 1, 2277 -3389.

Abugabah, A., Sanzogni, L. \& Alfarraj, O. (2015). Evaluating the impact of ERP systems in higher education. International Journal of Information and Learning Technology, 32(1), 45-64.

AIS e Library. (2017, September 20). The Importance of Digital Service Capabilities in Consumer-facing Industries. Retrieved from AIS elibrary, 16, 3-4.

Alhirz, H. \& Sajeev, M. A. (2015). Do cultural dimensions differentiate ERP acceptance? A study in the context of Saudi Arabia. Information Technology \& People, 28(1), 163-194.

Al-Mashari, M. (2017, April 25). A Process Change-Oriented Model for ERP Application. Retrieved from Semantic Scholar: httpspdfs.semanticscholar.org

Awa, H. O., Ojiabo, O. U. \& Orokor, L. E. (2017). Integrated technology-organization-environment (T-O-E) taxonomies for technology adoption. Journal of Enterprise Information Management, 27(4), 488-502.

Babaian, T., Xu, J. \& Wendy, L. (2017). ERP prototype with built-in task and process support. European Journal of Information Systems, 27(2), 189-206.

Buhrig, J., Schoormann, T. \& Knackstedt, R. (2018). Business Process Management in German Institutions of Higher Education: The Case of Jade University of Applied Science. In: vom Brocke J., Mendling J. (eds) Business Process Management Cases. Management for Professionals. Hannover: Springer.

Comuzzi, M. \& Parhizkar, M. (2017). A methodology for enterprise systems post-implementation change management. Emerald Publishing Limited. Journal of Industrial Management \& Data Systems, 117(10), 2241-2262.

Cresswell, W. J. (2018). Research Design. Quantitative, Qualitative, and Mixed Method Approaches. Michigan:: Sage Publications.

Debrosse-Bruno, M. M. (2017). Critical success factors (CSFs) for implementation of enterprise resource planning (ERP) systems in various industries, including institutions of higher education (IHEs). Maryland: ProQuest LLC.

Elmonem, M. A., Nasr, E. S. \& Gheith, M. H. (2017). Automating Requirements Elicitation of Cloud-Based ERPs. Cairo: Springer.

Gartner. (2019, November 5). Information Technology Gartner Glossary. Retrieved from Enterprise Resource Planning (ERP): https://www.gartner.com/en/information-technology/glossary/enterpriseresource-planning-erp

Jaradat, R. M. (2014, May 10). An instrument to assess individual capacity for system thinking. Retrieved from proquest.com: https://search.proquest.com/docview/1652469947?accountid=10612

Kalema, B. M., Olugbara, O. O. \& Kekwaletswe, R. M. (2014). Identifying Critical Success Factors: the case of ERP Systems in Higher Education. The African Journal of Information Systems, 6(3), 65-84. 
Kasemsap, K. (2018). The Role of Knowledge Transfer in Modern Organisations. Rajabhat: IGI Global.

Khan, F., Xuehe, Z., Atlas, F., Khan, K. U., Pitafi, A., Saleem, M. U. \& Khan, S. (2017). Impact of absorptive capacity and dominant logic on ERP assimilation in Chinese firms. International Entrepreneurship, 3(2), 81-99.

Peng, C. G. \& Miguel, N. (2017). Establishing an evidence-based 9D evaluation approach for ERP postimplementation. Industrial Management and Data Systems, 117(2), 398-424.

Ruivo, P., Oliviera, T. \& Mestre, A. (2017). Enterprise resource planning and customer relationship management value. Industrial Management and Data Systems, 117(2), 398-424.

Schniederjans, D. \& Yadav, S. (2013). Successful ERP implementation: an integrative model. Business Process Management Journal, 9(1), 364-398.

Sekaran, U. \& Bougie, R. (2018). Research Methods For Business. A Skill-Building Approach ( 7th Edition ed.). Sussex: John Wiley and Sons.

Skoumpopoulou, D. \& Waring, T. (2017). Cultural change through the implementation of an enterprise system: A UK university case study. Journal of Enterprise Information Management, 30(5), 809-830.

Somerville, M. M. \& Mirjamdotter, A. (2014). Information Experiences in the Workplace: Foundations for an Informed Systems Approach. Information Experience: Approaches to Theory and Practice, 9(1), 203220.

Srima, S. \& Wannapiroon, P. (2013). Development of Total Quality Management Information System (TQMIS) for Model School on Best Practice. International Journal of e-Education, e-Business, e-Management and e-Learning, 3(2), 148-150.

Tabbara, A. (2016, May 11). The use of ERP systems in higher education institutions in the U.A.E (Order No. 10130167). Retrieved from Proquest.com: https://search.proquest.com/docview/1816212966?accountid=10612

Thennakoon, D., Bandara, W., French, E. \& Mathiesen, P. (2018). What do we know about business process management training? Current status of related research and a way forward. Business Process Management Journal, 24(2), 487-500.

Turner, S. F., Cardinal, L. B. \& Burton, R. M. (2017). Research design for mixed methods: A triangulation-based framework and roadmap. Organisational Research Methods, 20(2), 243-267.

Wijawa, S. F., Kosala, R. R. \& Meyliana and Prabowo, H. (2017). Measurement of Enterprise Resources Planning. Berlin: Springer.

Wulf, J., Mettler, T. \& Brenner, W. (2017). Using a Digital Services Capability Model to Assess Readiness for the Digital Consumer. MIS quarterly executive, 16(3), 171-195.

Yatika \& Hasija. (2017). International Conference on Advanced Intelligent Systems and Informatics. International Journal of Emerging Research in Management \& Technology, 6(7), 2278-9359. 